\title{
FIRST DESCRIPTION OF A RIFAMPICIN- RESISTANT NEISSERIA MENINGITIDIS SEROGROUP Y STRAIN CAUSING RECURRENT INVASIVE MENINGOCOCCAL DISEASE IN HUNGARY
}

\author{
Ákos Tóth ${ }^{1,2} *$, BrigitTA Berta ${ }^{1}$, TAMÁs TiRCZKA ${ }^{1}$, CSILla JEKKEL $^{3}$, \\ ANITA ÁBrAHÁM ${ }^{3}$, ZOLTÁN PROHÁSZKA ${ }^{4}$, ZSÓFIA BOGNÁR ${ }^{1}$ and \\ TÍMEA ERDÖSI ${ }^{1}$ \\ ${ }^{1}$ National Center for Epidemiology, Budapest, Hungary \\ ${ }^{2}$ European Program for Public Health Microbiology Training (EUPHEM), European \\ Centre for Disease Prevention and Control (ECDC), Stockholm, Sweden \\ ${ }^{3}$ Szent László Hospital, Budapest, Hungary \\ ${ }^{4}$ Semmelweis University, Budapest, Hungary
}

(Received: 2 October 2016; accepted: 24 November 2016)

A Hungarian soldier previously immunized against Neisseria meningitidis by quadrivalent polysaccharide vaccine was twice infected with meningococci within six weeks. The patient was treated with ceftriaxone during both episodes and he successfully recovered. His close contacts received rifampicin prophylaxis. An investigation was performed to characterize the genetic background of the pathogens to ascertain if the recurrent invasive meningococcal disease was caused by the same strain and to find out the reason for reinfection. Both meningococci belonged to the fine type Y:P1.5-2,10-1:F4-1:ST-23. This is the first description of the Europe-wide prevalent $N$. meningitidis serogroup $\mathrm{Y}$ in Hungary. In the first episode, we found wildtype $r p o B$ allele in the non-culturable sample implying the susceptibility to rifampicin. The culturable isolate from the second episode proved resistant to rifampicin and had a point mutation in the $r p o B$ gene. The rifampicin resistance might have evolved during the prophylactic treatment of contacts. Previous immunization of the patient with polysaccharide vaccine was ineffective due to his immunodeficiency, thus immunization with conjugate vaccine was proposed. We have proposed the implementation of centralized rifampicin susceptibility testing of $N$. meningitidis strains within a defined time frame to intervene and administer appropriate prophylaxis to close contacts.

Keywords: serogroup Y, meningococcal vaccination, immunodeficiency, rifampicin resistance, surveillance

*Corresponding author; E-mail: tothakos0526@gmail.com 


\section{Introduction}

In Hungary, invasive meningococcal disease (IMD) is mandatorily notifiable and it is recommended to submit Neisseria meningitidis isolates or clinical samples - in case of non-culturable samples - for confirmation and molecular typing to the IMD National Reference Laboratory (NRL) of National Center for Epidemiology (NCE).

The incidence of IMD in Hungary varies between 0.17 and 1.00 notified cases per 100,000 population (mean 0.41/100,000) from 1988 to 2013 (Figure 1). In 2011, the notification rate was 0.67 cases per 100,000 population which is below the total European notification rate ( 0.77 cases per 100,000 population) [1]. However, the case fatality rate of IMD was higher (17.9\%) than the European average (8.7\%) in 2011 [1].

According to the NRL data, serogroups B and C caused the most cases of IMD and serogroup B was most prevalent (average 74\% of known serogroups/ year, 1988-2013) (Figure 1) in Hungary. During this period, there were two epidemiological seasons (1999/2000 and 2010/2011) when serogroup C was reported in a higher proportion than serogroup B due to two outbreaks among soldiers and high school students, respectively (unpublished data, source: Surveillance of IMD, National Center for Epidemiology, Hungary).

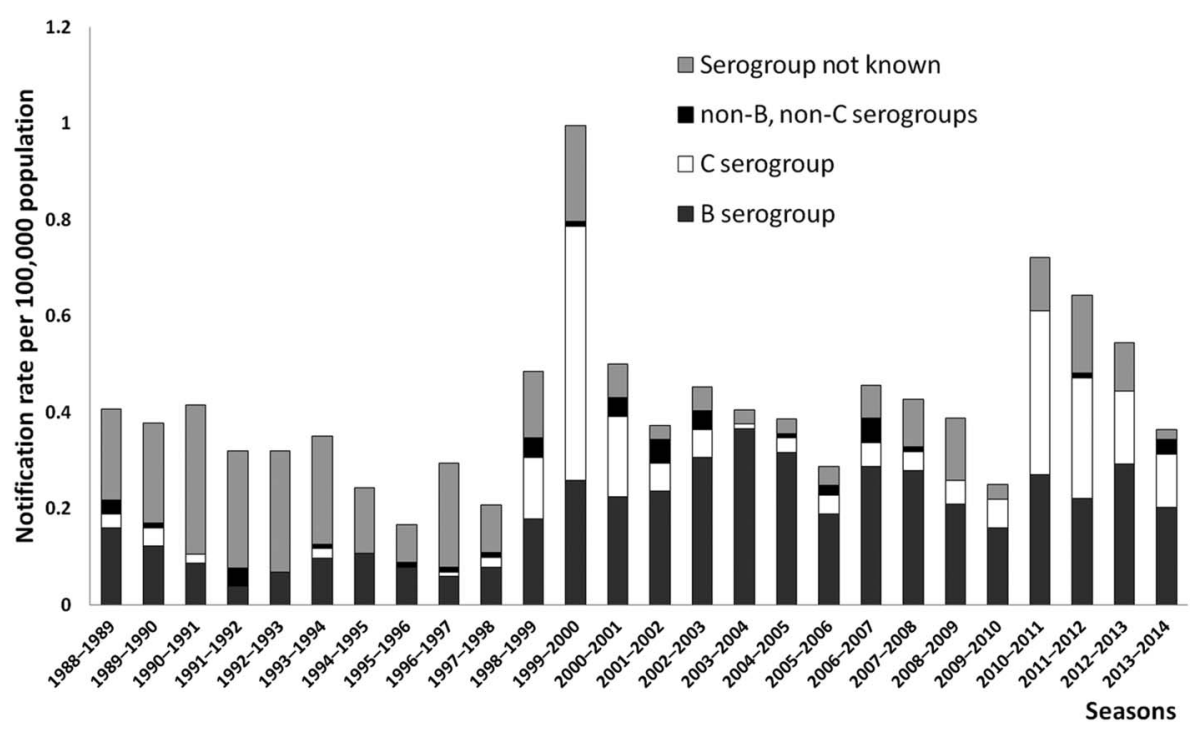

Figure 1. Notification rate of invasive meningococcal disease by serogroup in Hungary, 1988-2013 (Source: Surveillance of IMD, National Center for Epidemiology, Hungary) 
Although, the proportion of $N$. meningitidis serogroup $\mathrm{Y}(\mathrm{NmY})$ is increasing among notified IMD cases in Europe [2], in Hungary the first NmY IMD case was confirmed in 2013 which is presented here as a case report.

\section{Case Report}

A 24-year-old male patient was hospitalized with clinical suspicion of meningococcal meningitis to the Department of Infectious Diseases No. III in Szent László Hospital, Budapest on 15 October 2013. He was a professional soldier with an unremarkable medical history and no regular medications. Because he repeatedly joined in military missions, he was immunized with quadrivalent (A, C, Y, W) meningococcal polysaccharide vaccine, 4 years and 1 year prior to the onset of symptoms, respectively.

He was admitted to the department with a one-day history of headache, fever, vomiting, and exanthemas. During the examination he appeared ill, psychometrically agitated, presented with stiffness of the neck and petechiae and purpura were observed on the torso and extremities. His body temperature was $37.2{ }^{\circ} \mathrm{C}$, blood pressure was $116 / 70 \mathrm{mmHg}$, pulse rate was 85 beats $/ \mathrm{min}$. The patient didn't show any focal neurological signs and he was not disorientated. Cranial CT scan without the administration of contrast material revealed no evidence of acute intracranial haemorrhage, territorial infarction, or intracranial mass lesion. Lumbar puncture was performed, the cerebrospinal fluid (CSF) was purulent and microscopy revealed Gram-negative diplococci in the CSF smear. No bacteria grew from the CSF and the agglutination test by Wellcogen kit was negative for $N$. meningitidis and Streptococcus pneumoniae. The CSF sample was sent to the NCE to confirm the suspicion of IMD. For detection of the meningococcal DNA in CSF, Real Time, and conventional PCRs using species (target gene $\operatorname{ctr} A$ ) and serogroup specific $\left(\operatorname{sia} D_{\mathrm{WY}}, \operatorname{sia} D_{\mathrm{B}}, \operatorname{sia} D_{C}\right)$ primers were performed $[3,4]$. The CSF sample proved to be positive for serogroup Y meningococcus. Immediately after admission of the patient, ceftriaxone $(2 \times 2 \mathrm{~g} /$ day $)$ was given and continued for 10 days. After 10 days in hospital care, he recovered without any complications and was discharged home. Investigation and management of contacts was initiated by the NCE and performed by local authorities within $24 \mathrm{~h}$ after raising the suspicion of IMD. Based on the results of contact tracing the patient had been visiting his girlfriend and her family at the time of onset of the symptoms. These five adult family members and additional eight health care workers were given rifampicin $(2 \times 600 \mathrm{mg}$ for 2 days $)$ according to the Hungarian guideline for management of IMD [5]. The patient participated in military training before visiting his girlfriend; therefore, additional contact tracing was performed 
by both the Hungarian Defence Forces and Public Health and Epidemiological Service. Thirty soldiers identified as close contacts were given ciprofloxacin $(2 \times 500 \mathrm{mg})$ as prophylaxis. During the incubation period, no symptoms were observed among close contacts.

Six weeks later, the same patient was readmitted to the same hospital with a one-day history of fever, sore throat, mild headache, and exanthemas. Apart from these symptoms, he was in good condition, the body temperature was normal, blood pressure was $150 / 80 \mathrm{~mm} \mathrm{Hg}$, and pulse rate was 103 beats/min. On examination, he was alert and orientated, no focal neurological signs nor neck stiffness were present. There were maculopapular exanthemas on the extremities with a few purpura and petechia. Ceftriaxone $(2 \times 2 \mathrm{~g} /$ day $)$ was administered and continued again for 10 days, then the patient was discharged in a good condition. $N$. meningitidis was cultured from blood culture taken before commencing antibiotic therapy. At the NCE, the isolate was phenotyped using slide agglutination with monoclonal antisera (Remel Europe, England) and antibiotic susceptibility was determined by use of gradient minimal inhibitory concentration (MIC) tests (Liofilchem, Italy) and interpreted according to the EUCAST guidelines [6]. The causative agent was again NmY with the following MIC values: penicillin, $0.064 \mathrm{mg} / \mathrm{L}$; ceftriaxone, $0.002 \mathrm{mg} / \mathrm{L}$; ciprofloxacin, $0.016 \mathrm{mg} / \mathrm{L}$; and rifampicin, $>32 \mathrm{mg} / \mathrm{L}$.

Based on the second epidemiological investigation of close contacts, one family member and five healthcare workers were given rifampicin $(2 \times 600 \mathrm{mg}$ for 2 days) prophylaxis. Furthermore, 165 soldiers were given $2 \times 500 \mathrm{mg}$ ciprofloxacin according to the recommendation of the Hungarian Defence Forces, Public Health and Epidemiological Service. During the second episode, one soldier contact showed upper respiratory symptoms and he was observed for 10 days. No IMD developed.

Meningococci with identical serogroup - detected in Hungary for the first time - suggested that the two episodes may have been related to each other and the suspected recurrent infection probably due to the immunodeficient status of the patient. Moreover, the detected rifampicin resistance could imply unsuccessful antibiotic prophylaxis of contacts who had taken rifampicin during the first episode and the strain persisted in symptomless carriers.

Therefore, an investigation was performed to characterize the genetic background of the pathogens in order to ascertain if the recurrent IMD was caused by the same pathogen and to determine the cause of the suspected reinfection.

The pathogens from both episodes were characterized by multilocus sequence typing and sequencing of variable regions of por $A$ and $\operatorname{fet} A$ genes (called fine typing) according to the recommendation of the European 
Meningococcal Disease Society [7]. The presence of mutations associated with rifampicin resistance in specific region of $r p o B$ gene, encoding the $\beta$ subunit of bacterial RNA polymerase was investigated by sequencing [8]. Due to the recurrent IMD, diagnostic tests for immunodeficiency were performed [9].

Both meningococci belonged to the serogroup Y, sequence type ST-23 (ST-23 complex/Cluster A3) and had identical fine type (Y:P1.5-2,10-1:F4-1). In the first episode, wild-type rроB allele implying susceptibility to rifampicin of the pathogen was found. The isolate from the second episode had a point mutation at amino acid residue S557 (S557F) in the rpoB gene associated with high level rifampicin resistance [8]. The patient was screened for terminal complement component defects, and C8 component absence was revealed. Testing for HIV antibodies was negative. Immunization with conjugate vaccine was proposed for the patient to prevent him from developing new IMD in the future.

\section{Discussion}

During the last 10 years, $\mathrm{NmY}$ has increased importance in Europe [1]. In 2010 and 2011, the highest relative proportion of NmY IMD among all serogroups was reported by Scandinavian countries (up to 55\%), followed by the central/western European countries (5\%-10\%) but no NmY IMD was detected in Hungary [2]. To our best knowledge, this is the first report on a NmY pathogen that belonged to Y:P1.5-2,10-1:F4-1:ST23 type in Hungary. According to the data of the European Meningococcal Epidemiology in Real Time (EMERT) database, that has collected molecular typing data for N. meningitidis in Europe since 2007, this particular type was the most prevalent among reported types of NmY strains [10]. This sequence-based typing method gives opportunity to evaluate the probable relationship between two or more strains, even if it is a non-culturable pathogen. The fine types of our both meningococci were identical which suggested that the recurrence of IMD with the same strain was highly likely.

The C8 component absence in terminal complement pathways can explain the recurrence of the IMD [11], and the ineffectiveness of polysaccharide vaccine for NmY [12] also. In case of complement deficiency immunization with conjugate vaccine is the gold standard preventive measure against IMD in line with international recommendation [13].

Many European countries including Hungary recommend rifampicin as first choice for prophylaxis. Rifampicin resistance is rare in Europe but several studies have observed the emergence and spread of rifampicin-resistant strains among carriers after prophylaxis [14]. Similarly, in the second IMD episode the resistance probably evolved during the prophylactic treatment of contacts. On this occasion, 
six contacts were given rifampicin prophylaxis since the administration of the drug was delivered immediately after the notification of IMD and rifampicin resistance was confirmed only several days later at the NCE. By the time this finding became known, the contacts had finished the prophylactic therapy and the 10-day incubation period had been passed [15]. Due to the low IMD incidence in Hungary determination of rifampicin MIC value is a rarely requested test and is not available within several diagnostic laboratories in Hungary.

Considering that in the last 5 years no rifampicin resistance was observed among culturable meningococci isolates in Hungary, the emergence of rifampicin resistance is of concern. Therefore, we have proposed the implementation of centralized rifampicin susceptibility testing of $N$. meningitidis strains at the NCE within a defined time frame of 4-8 days in order to intervene and administer appropriate prophylaxis to close contacts if a resistant strain is detected. The implementation of the proposed modifications could improve the effectiveness of meningococcal public health management.

\section{Acknowledgements}

The authors would like to thank Ferenc Magyaros, MD for his help, the ECDC EUPHEM coordinators, and Ivelina Damjanova, EUPHEM supervisor for their valuable advices. This case report made use of the European Meningococcal Epidemiology in Real Time (EMERT) website (http://emgm.eu/emert/) developed by Keith Jolley sited at the University of Oxford. The development of this site has been funded by the Wellcome Trust and the European Union.

\section{Conflict of Interest}

There is no conflict of interest present connected to the work.

\section{References}

1. European Centre for Disease Prevention and Control: Surveillance of Invasive Bacterial Diseases in Europe, 2011. ECDC, Stockholm, 2013.

2. Bröker, M., Bukovski, S., Culic, D., Jacobsson, S., Koliou, M., Kuusi, M., Simões, M. J., Skoczynska, A., Toropainen, M., Taha, M. K., Tzanakaki, G.: Meningococcal serogroup $\mathrm{Y}$ emergence in Europe: High importance in some European regions in 2012. Hum Vaccines Immunother 10, 1725-1728 (2014).

3. Corless, C. E., Guiver, M., Borrow, R., Edwards-Jones, V., Fox, A. J., Kaczmarski, E. B.: Simultaneous detection of Neisseria meningitidis, Haemophilus influenzae, and 
Streptococcus pneumoniae in suspected cases of meningitis and septicemia using real-time PCR. J Clin Microbiol 39, 1553-1558 (2001).

4. Mothershed, E. A., Sacchi, C. T., Whitney, A. M., Barnett, G. A., Ajello, G. W., Schmink, S., Mayer, L. W., Phelan, M., Taylor, T. H., Bernhardt, S. A., Rosenstein, N. E., Popovic, T.: Use of real-time PCR to resolve slide agglutination discrepancies in serogroup identification of Neisseria meningitidis. J Clin Microbiol 42, 320-328 (2004).

5. Johan Béla Országos Epidemiológiai Központ: A Johan Béla Országos Epidemiológiai Központ Módszertani Levele a meningococcus invazív betegségröl. EPINFO S1, 2000. Available at http://semmelweis.hu/korhazhigiene/files/2012/06/Meningocossus1.pdf

6. The European Committee on Antimicrobial Susceptibility Testing: Breakpoint tables for interpretation of MICs and zone diameters. Available at http://www.eucast.org.

7. http://neisseria.org/nm/typing/.

8. Taha, M. K., Hedberg, S. T., Szatanik, M., Hong, E., Ruckly, C., Abad, R., Bertrand, S., Carion, F., Claus, H., Corso, A., Enríquez, R., Heuberger, S., Hryniewicz, W., Jolley, K. A., Kriz, P., Mollerach, M., Musilek, M., Neri, A., Olcén, P., Pana, M., Skoczynska, A., Sorhouet Pereira, C., Stefanelli, P., Tzanakaki, G., Unemo, M., Vázquez, J. A., Vogel, U., Wasko, I.: Multicenter study for defining the breakpoint for rifampin resistance in Neisseria meningitidis by rpoB sequencing. Antimicrob Agents Chemother 54, 3651-3658 (2010).

9. Réti, M., Farkas, P., Csuka, D., Rázsó, K., Schlammadinger, Á., Udvardy, M. L., Madách, K., Domján, G., Bereczki, C., Reusz, G. S., Szabó, A. J., Prohászka, Z.: Complement activation in thrombotic thrombocytopenic purpura. J Thromb Haemost 10, 791-798 (2012).

10. European Meningococcal Epidemiology in Real Time (EMERT). Available at http://emert. eu/emert/.

11. Kvalsvig, A. J., Unsworth, D. J.: The immunopathogenesis of meningococcal disease. J Clin Pathol 56, 417-422 (2003).

12. Fijen, C. A., Kuijper, E. J., Drogari-Apiranthitou, M., Van Leeuwen, Y., Daha, M. R., Dankert, J.: Protection against meningococcal serogroup ACYW disease in complement-deficient individuals vaccinated with the tetravalent meningococcal capsular polysaccharide vaccine. Clin Exp Immunol 114, 362-369 (1998).

13. Cohn, A. C., MacNeil, J. R., Clark, T. A., Ortega-Sanchez, I. R., Briere, E. Z., Meissner, H. C., Baker, C. J., Messonnier, N. E., Centers for Disease Control and Prevention (CDC): Prevention and control of meningococcal disease: Recommendations of the Advisory Committee on Immunization Practices (ACIP). MMWR Recomm Rep 62, 1-28 (2013).

14. European Centre for Disease Prevention and Control: Public Health Management of Sporadic Cases of Invasive Meningococcal Disease and Their Contacts. ECDC, Stockholm, 2010.

15. Centers for Disease Control and Prevention: Meningococcal disease. In Hamborsky, J., Kroger, A., Wolfe, S. (eds): Epidemiology and Prevention of Vaccine-Preventable Diseases, 13th Edition. Public Health Foundation, Washington DC, 2015, pp. 231-246. 